\title{
Special Features of the Educational Component "Design of Devices on Microcontrollers and FPGA"
}

\author{
Iryna Svyd \\ ORCID 0000-0002-4635-6542 \\ Department of Microprocessor \\ Technologies and Systems \\ Kharkiv National University of Radio \\ Electronics \\ Kharkiv, Ukraine \\ iryna.svyd@nure.ua \\ Oleg Zubkov \\ ORCID 0000-0002-8528-6540 \\ Department of Microprocessor \\ Technologies and Systems \\ Kharkiv National University of Radio \\ Electronics \\ Kharkiv, Ukraine \\ oleh.zubkov@nure.ua
}

\author{
Oleksandr Vorgul \\ ORCID 0000-0002-7659-8796 \\ Department of Microprocessor \\ Technologies and Systems \\ Kharkiv National University of Radio \\ Electronics \\ Kharkiv, Ukraine \\ oleksandr.vorgul@nure.ua \\ Valeriia Chumak \\ ORCID 0000-0002-2403-020X \\ Department of Microprocessor \\ Technologies and Systems \\ Kharkiv National University of Radio \\ Electronics \\ Kharkiv, Ukraine \\ valeriia.chumak@nure.ua
}

\author{
Valerii Semenets \\ ORCID 0000-0001-8969-2143 \\ Department of Microprocessor \\ Technologies and Systems \\ Kharkiv National University of Radio \\ Electronics \\ Kharkiv, Ukraine \\ valery.semenets@nure.ua \\ Natalia Boiko \\ ORCID 0000-0002-7524-729X \\ Department of Microprocessor \\ Technologies and Systems \\ Kharkiv National University of Radio \\ Electronics \\ Kharkiv, Ukraine \\ natalia.boiko@nure.ua
}

\begin{abstract}
Questions of features of the distribution and the implementation of the educational component "Design of devices on microcontrollers and field programmed logical gate arrays" with the support of all stakeholders' requirements to the latest technical knowledge are considered. Structural and technical description of the educational component is discussed.
\end{abstract}

Keywords-technical education, laboratory workshop, design of devices, laboratory model, MatLab, microcontroller, CPLD, FPGA, Xilinx, STM32, dashboard.

\section{INTRODUCTION}

Education of students at the Department of Microprocessor Technologies and Systems (MTS) of Kharkiv National University of Radio Electronics (KNURE) began in the 2018-2019 academic year. The main task of the fundamental department of MTS is to strengthen the quality of training of professional engineers in accordance with European standards in the field of microprocessor technologies and systems [1-3].

The curriculum of the discipline "Design of devices on microcontrollers and FPGA" was developed in close cooperation with colleagues from the University of Limoges (France), Lublin University of Technology (Poland) and Istanbul Technical University (Turkey). The best European training practices have been taken into account in the development of the curriculum.

In modern society, much attention is paid to quality of training of technical specialists as a component of scientific and technological progress. Research and teaching staff of KNURE in accordance with the mission and main direction of the university pay sufficient attention to the development and implementation of new technologies in technical education [4-10].

\section{DESCRIPTION OF THE CURRICULUM}

When developing the curriculum in the discipline "Design of devices on microcontrollers and FPGA" it was taken into account the best European practices of partner universities, the wishes of stakeholders, scientific and pedagogical experience of university professors: the maximum practical component; solution of block consecutive practical problems; division of discipline into related logical modules; training on modern equipment; use of the latest technologies and so on.

The discipline "Design of devices on microcontrollers and FPGA" is taught in the cycle of general and special professional training for students of the first (bachelor's) level of higher education at the faculties of the university: Faculty of Automatics and Computerized Technologies; Faculty of Information Radio Technologies and Technical Information Security; Faculty of Electronic and Biomedical Engineering; Faculty of Infocommunications. The discipline is studied by students of the following specialties: 125 Cybersecurity; 151 Automation and computer-integrated technologies; 152 Metrology and information-measuring equipment; 163 Biomedical Engineering; 171 Electronics; 172 Telecommunications and radio engineering; 173 Avionics.

Materials of the discipline "Design of devices on microcontrollers and FPGA" in the amount of 10 ECTS credits are divided into three modules:

- Modeling of digital signals by means of MATLAB and VHDL (2 ECTS credits);

- Microcontrollers (4 ECTS credits);

- FPGA (4 ECTS credits).

In the distribution of auditorium hours between types of classes, it is paid a special attention to the practical 
orientation of the discipline. Therefore, $75 \%$ of the study time is spent on laboratory workshops, and $25 \%$ of the time is spent on lectures.

The study of each module of the discipline is designed for one semester. Each module includes lectures, practical classes and labs. There are nine laboratory works in each module. Laboratory work of the first module is performed in two academic hours. While the laboratory work of the second and third modules are performed in four academic hours.

\section{A. Simulation of Digital Signals Using MATLAB and VHDL}

This module is aimed at studying the mathematical foundations of digital signal processing and mastering the basic algorithms used for analysis and synthesis of digital signal filtering devices. The laboratory workshop is performed using MatLab software or Octava [11]. The materials of the module are aimed at obtaining the following results by the applicant:

- calculate the spectral, temporal and correlation characteristics of discrete signals, find their $\mathrm{Z}$ image;

- determine the system function of digital filters;

- calculate the time and frequency characteristics of digital filters;

- build block diagrams of digital filters in direct, canonical, cascade and parallel forms as well as its transposed variants;

- synthesize filters with infinite and finite impulse characteristics.

When performing a laboratory workshop is modeled:

- discrete signal;

- linear discrete system;

- discrete Fourier transform;

- $\quad$ synthesis of FIR filters by the window method;

- synthesis of FIR and IIR filters by the method of the best uniform approximation;

- synthesis of IIR filters by bilinear z-transformation;

- synthesis of FIR and IIR filters using FDATool and FilterBuilder in order to obtain VHDL description of the filter given.

\section{B. Microcontrollers}

This module is aimed at studying the programming of modern microprocessors STM32F407VGT manufactured by ST in $\mathrm{C}++$, in-circuit debugging of microprocessor software. Much attention is paid to learning the programming language, working with software packages IAR Embedded Workbench for ARM, STM32CubeMX and STM32CubeIDE, to write and debug programs, the use of these microprocessors in digital devices for transmission and processing of information. The laboratory workshop is performed on STM32F4 DISCOVERY models using MatLab, STM32CubeMX, STM32CubeIDE, IAR Embedded
Workbench for ARM v 8.3 Kikstart software [12]. The materials of the module are aimed at obtaining the following results by the applicant:

- develop schematics and compose the embedded software for such devices as: keyboard controller, PWM and analog signal generator, analog sensor meter, digital signal filtering device, UART communication device, graphic display control device, etc.;

- debug software using STM32CubeMX, STM32CubeIDE and IAR Embedded Workbench for ARM simulation packages;

- program the microprocessor and test the software composed.

When performing a laboratory workshop the following tasks are carried out:

- study of the architecture and principles of operation of the I / O ports of the processor STM32F407VGT;

- study of programming timers-counters;

- study of programming of the built-in digital-to-analog converter;

- study of programming of the built-in analog-to-digital converter;

- digital filtering of analog signal;

- study of programming of the built-in asynchronous interface UART;

- data storage in the internal flash memory of the processor;

- control of LCD indicator ILI9328 through the built-in FSMC interface;

- development of graphic interface with the ILI9328 indicator.

\section{FPGA}

This module is aimed at studying the architecture and programming of modern programmable logic integrated circuits of the Artix-7 FPGA family manufactured by Xilinx, VHDL digital device design language and debugging methods and tools using the Vivado CAD software package; use of FPGA for the development of digital signal processing devices. The laboratory workshop is performed on Artix-7 FPGA Xilinx models using CAD Vivado HLx Design Suite 2018.2, MatLab [13-15]. The materials of the module are aimed at obtaining the following results by the applicant:

- solve at the hardware and software level the task of building specialized hardware;

- create models of digital systems at different levels of description: abstract, schematic and software;

- master the methods of decomposition of the system, which are implemented in hardware and software;

- implement a description of logic (program) of medium complexity in VHDL; 
- develop embedded microprocessor systems based on FPGA.

When performing a laboratory workshop are carried out:

- execution of logic modeling of digital input signals;

- 7-segment indicator control;

- formation of a periodic sequence of pulses;

- PWM signal generation; formation of a sinusoidal analog signal;

- control of analog-to-digital converter;

- analog-to-digital and digital-to-analog conversion.

\section{EDUCATION ORGANIZATION OF THE DISCIPLINE}

Prior to the beginning of the semester, all educational materials of the discipline are posted on the website dl.nure.ua, which implements the computer network educational environment by means of the platform based on the Moodle. Each student gets an access to the courses. This system allows the students to plan their studies more rationally and prepare for classes in advance. Also, when studying the discipline, students have the opportunity to participate in research at the Department of MTS.

The discipline has implemented an accumulative system of points, which takes into account: class attendance, reports on laboratory work, tests; also, above the maximum score, the scientific work of students is taken into account.

During the laboratory work, students receive a large number of graphs, screens of modeling and of verification stages, program codes, photos of the boards, etc. Students submit all completed reports exclusively in electronic form.

Such a system of work on the discipline was introduced at the beginning of the discipline.

\section{CONCLUSIONS}

Discipline "Design of devices on microcontrollers and FPGA" corresponds to modern trends in society for the training of highly qualified technicians in the field of microprocessor systems and technologies. It also makes a great contribution to the formation of specialists in embedded systems, which corresponds to the areas of IoT and IIoT.

The proposed distribution of types of classes in the discipline "Design of devices on microcontrollers and FPGA" allows the best way to ensure the practical orientation of training.

This approach made it possible to greatly facilitate the transition of teachers and students to remote work in quarantine conditions.

It is planned to further implement a system of joint work of students on projects and the possibility of remote access to hardware platforms at the laboratory workshop.

\section{REFERENCES}

[1] Valerii Semenets, Liliia Saikivska, Iryna Svyd, Oleksandr Maltsev. Trends in Training Modern Technicians. // First International Scientific and Practical Conference «Theoretical and Applied Aspects of Device Development on Microcontrollers and FPGAs» MC\&FPGA-2019, Kharkiv, Ukraine, July 26-27, 2019. - Kharkiv: NURE, MC\&FPGA, $2019 . \quad$ - $\quad$ P. 35-36. DOI: 10.35598/mcfpga.2019.013

[2] V. Semenets, I. Svyd and L. Saikivska, "Methods of improving the quality of preparation of technical specialists", in Engineering education: challendes and developments : materials of the IX International Scientific and Methodological Conference, Minsk, Belarus, 2018, pp. 415-416.

[3] Semenets V.V., Svyd I.V., SaikivskaL.F. Current trends in the training of specialists in the technical field. // Specialized Exhibition «KharkivProm Days. Production and efficiency». Collection of materials of the forum section «Automation, electronics and robotics. Development Strategies and Innovative Technologies». - Kharkiv, KNURE, Exhibition Company ADT, 2019. - P. 4-5.

[4] Svyd I.V., Litvinenko O.V., Bilotserkivets O.G. Features of designing digital devices based on Xilinx FPGA in CAD Vivado HLx Design Suite. // Specialized Exhibition «KharkivProm Days. Production and efficiency». Collection of materials of the forum section «Automation, electronics and robotics. Development Strategies and Innovative Technologies». - Kharkiv, KNURE, Exhibition Company ADT, 2019. - P. 43-44.

[5] V. Semenets, V. Levikin and V. Sayenko, "Research and analysis of the didactic policy of the university in the training of specialists in information technology", Automated control systems and devices, vol. 175, pp. 4-14, 2018.

[6] V. Kobzev, V. Semenets and V. Filatov, "Components of the information system for monitoring the quality of education in Kharkov National University of Radio Electronics", in 7th Int. scientific and technical conf. Information systems and technologies (IST-2018), Kharkiv-Koblevo, 2018, pp. 51-54.

[7] I. Tarasov. Organization of the educational process in the design of digital devices using an initial level based boards FPGA Spartan-6 company Xilinx. Components and Technologies, 2011,12, pp.10-14.

[8] Avrunin O.G. Basics of VDHL language for designing digital devices on FPGA: a textbook. / O.G. Avrunin, T.V. Nosova, V.V. Semenets. Kharkiv: KNURE, 2018. - 196 p.

[9] V. Semenets, "Technical aspects for development laboratory base for learning FPGA and microcontroller systems.", in 10th International Conference The Experience of Designing and Application of CAD Systems in Microelectronics, Lviv-Polyana, Ukraine, 2009, p. 145.

[10] V. Semenets, V. Kauk, O. Avrunin. "The advanced technology of remote training at the initial process" ["Vprovadjennya tehnologiy dystantsiynogo navchannya u navchalnii protses"], High School, 2009. - No. 5 .- P. 40- 45.

[11] Digital signal processing and MATLAB: textbook. allowance / A.I. Solonina, D.M. Klionsky, T.V. Merkucheva, S.N. Perov. - SPb .: BHV-Petersburg, 2013 .- 512 p.

[12] Geoffrey Brown. Discovering the STM32 Microcontroller. USA, 2016. -244 p.

[13] V. Soloviev, Architecture of the CPLD of the firm XILINX: CPLD and FPGA of the 7th series. Moscow: Hotline - Telecom, 2016, p. 392.

[14] "Artix-7 FPGAs Data Sheet:DC and AC Switching Characteristics. Product Specification. DS181 (v1.25) June 18, 2018", Xilinx.com, 2018. [Online]. Available: https://www.xilinx.com/support/ documentation/data_sheets/ds181_Artix_7_Data_Sheet.pdf.

[15] Design of digital systems using VHDL language / Semenets V.V., Hahanova I.V., Hahanov V.I. - Kharkiv: KhNURE, 2003.-492 p. 